\title{
Princípios de direito socioambiental na evolução das noções de direito, estado e justiça: novos conceitos, sujeitos e institucionalidades a serem consideradas
}

Danielle de Ouro Mamed ${ }^{*}$

\section{INTRODUÇÃO}

As transformações ocorridas no meio ambiente devido às constantes crises envolvendo os recursos naturais possuem consequências largamente demonstradas pelos mais diversos estudos científicos.

O impacto dessas mudanças, são refletidos na qualidade do meio ambiente e, por consequência, na qualidade das condições de vida humana. O modelo de Direito adotado pela sociedade contempoânea tem passado por constantes mutações, de modo que se nota o esforço cotidiano dos sistemas que compõem o Estado de Direito de adequar-se aos novos valores impostos pela sociedade.

Entre esses valores, encontram-se a crescente valorização dos bens ambientais e das peculiaridades sociais, principalmente pela influência de paradigmas como o desenvolvimento sustentável e do socioambientalismo, os quais tratam de questionar a manutenção de um modo de vida e de produção incompatível com a sua própria sobrevivência.

Nesse sentido, tendo em vista as negatividades ocasionadas pelas crises relacionadas ao meio ambiente, surgem algumas respostas advindas das esferas de poder político, inclusive nos contextos de construção e aplicação das normas jurídicas que, absorvendo esses novos valores sociais, tenta incorporá-los ao mundo rígido das normas, estabelecendo novos elementos para as teorias do Direito e do Estado. 
Os elementos axiológicos, portanto, têm sido fundamentais para uma constante revolução jurídica, trazendo formas de relativizar as normas pela utilização de princípios, que devem reger tanto a formulação das leis quanto sua aplicação. Nesse contexto, apresentam-se os valores de caráter socioambiental, modificando alguns importantes aspectos no Direito e ajudando a construir sistemas jurídicos mais voltados às complexidades da sociedade e do meio ambiente.

\section{CRISE DO DIREITO, DO ESTADO E DA JUSTIÇA FRENTE OS PROBLEMAS SOCIOAMBIENTAIS}

O funcionamento do Estado de Direito, notadamente, fundamenta sua atuação na existência de sistemas jurídicos, compostos de normas jurídicas. O Direito constitui um sistema que visa proporcionar a existência pacífica da sociedade, que o legitima primeiramente pela noção de "contrato social", pela qual se pressupõe que a sociedade abre mão de parte de sua liberdade para tornar possível a coexistência dos interesses conflitantes.

Na construção e consolidação de normas jurídicas, impõe-se a observância de uma série de critérios, dentre os quais, a criação de normas que motivem condutas consideradas socialmente desejáveis e que exprimam a vontade do povo, titular máximo do poder político de instituir normas que observem os valores defendidos pela sociedade. Para Hans Kelsen, a regulação da conduta humana precisa dialogar diretamente com a noção de motivação, para que os indivíduos se abstenham ou executem atos nocivos ou úteis à sociedade (KELSEN, 2005, p. 21).

Seguindo a lógica constitucionalista, portanto, nota-se que o Direito dispõe de mecanismos para nortear essas condutas à paz social, incluindo-se, obviamente, a necessidade de ações ou abstenções voltadas à sanidade do meio ambiente, essencial à qualidade de vida e à própria manutenção dela, havendo, nesse sentido, um relevante papel atribuído à proteção do meio ambiente em âmbito constitucional.

Partindo do pressuposto de que os sistemas normativos, especialmente o sistema constitucional, devem ser orientados à preservação dos princípios relevantes para a sociedade, especialmente em matéria de meio ambiente, mostrase necessário (para a análise que se pretende neste trabalho) relembrar como os valores relacionados aos direitos socioambientais tem evoluindo nos sistemas normativos constitucionais.

A crescente inclusão de normas de proteção ambiental, notadamente, constitui uma preocupação decorrente da crise ambiental que, partindo da escassez dos recursos naturais e da queda na qualidade ambiental. Além disso, a crise ambiental também afeta as diversas sociedades culturalmente diferenciadas pois, 
A destruição do meio ambiente natural também caminha com o fim do modo de vida tradicional e auto-suficiente das comunidades rurais: propaganda do estilo de vida ocidental é veiculada em todo o mundo, sem o menor esclarecimento. (CAPRA, 2006, p. 158-159)

Em que pese a gravidade da crise em torno do meio ambiente, nota-se que as respostas fornecidas pela sociedade e pelos detentores do poder político não podem ser consideradas como suficientes para conter o avanço de suas consequências negativas:

Verifica-se que, tanto as ideologias liberais como as socialistas, não souberam lidar com a crise ambiental, considerando que o capitalismo industrialista, no primeiro caso, e o coletivismo industrialista, no segundo, puseram em prática um modelo industrial agressivo aos valores ambientais da comunidade (LEITE, 2003, p. 22).

Assim, percebe-se que o avanço da crise ambiental acompanha o desenvolvimento do modo de produção capitalista, que, quanto mais avançado, maior é o agravamento da crise, pois, quanto mais a sociedade se torna "próspera, urbana, tecnologicamente avançada, economicamente dinâmica, e inovadora no campo da química", mais complexo e urgente se torna o problema das externalidades negativas da atividade econômica, pelo que se acentua a necessidade de intervenção e controle governamental. (CAPELLETTI, 1993, p. 36).

Esta ineficiência dos mecanismos para proteção do meio ambiente, em que pesem os esforços para chegar ao contrário, encontra como ponto de partida uma racionalidade voltada para o desenvolvimentismo a todo custo, que atualmente vem sendo combatida por meio de valores sociais que defendem outros elementos de importância para a sociedade, como por exemplo, o direito a um ambiente sadio, o paradigma da sustentabilidade e a responsabilidade intergeracional.

A questão ambiental, de forma sintética, traz consideráveis avanços à teoria do Direito, especialmente em relação a três aspectos específicos: a) a institucionalização de um Direito voltado aos problema socioambientais; b) a configuração de um Estado de Direito Ambiental e c) uma nova categoria para a ideia de justiça, pautada na Justiça Ambiental.

\subsection{Socioambientalismo e as novas configurações do Direito}

Tendo em vistas os novos valores sociais de defesa do meio ambiente e das sociedades dele dependentes, foi formulado o conceito de Socioambientalismo: 
O socioambientalismo foi construído com base na ideia de que as políticas públicas ambientais devem incluir e envolver as comunidades locais, detentoras de conhecimentos e de práticas de manejo ambiental. Mais do que isso, desenvolveu-se com base na concepção de que, em um país pobre e com tantas desigualdades sociais, um novo paradigma de desenvolvimento deve promover não só a sustentabilidade estritamente ambiental - ou seja, a sustentabilidade de espécies, ecossistemas e processos ecológicos como também a sustentabilidade social - ou seja, deve contribuir também para a redução da pobreza e equidade. Além disso, o novo paradigma deve promover e valorizar a diversidade cultural e a consolidação do processo democrático no país, com ampla participação social na gestão ambiental. (SANTILLI, 2005, p. 56).

Esse processo, no Brasil teve na redemocratização, por meio da Constituição de 1988, um marco essencial, para seu desenvolvimento, uma vez que se nota a emergência de distintos movimentos sociais, que reivindicavam seus direitos, como por exemplo, o movimento indígena em prol da demarcação de suas terras; os trabalhadores pleiteando direito à greve; e os trabalhadores rurais defendendo a necessidade de reforma agrária (SANTILLI, 2005, p. 56).

Portanto, nota-se que a reivindicação de direitos socioambientais possui um cunho marcadamente de defesa de direitos coletivos ou difusos, com ampla participação dos movimentos sociais (a exemplo das questões sociais em geral e da problemática ambiental, que incide diretamente sobre a vida em sociedade), além de fomentar o debate a respeito da diversidade sociocultural que precisa ser considerada para a institucionalização de políticas públicas. Dessa forma, pensar em direitos socioambientais remete, necessariamente, ao respeito às diversas formas de organização social, fomento à democracia e, finalmente à necessidade de mudanças na gestão dos recursos naturais em face dos fatores negativos advindos do modo de produção atual, sendo que a Constituição de 1988, como se nota, acabou refletindo as demandas da sociedade, marcando-as na Carta Magna brasileira.

Outra transformação importante remonta à formação de uma Estado Ambiental, ao menos no âmbito brasileiro, uma vez que a tutela do meio ambiente pelo Estado Brasileiro está amparada constitucionalmente, sendo a proteção do meio ambiente dever de todos. A defesa dos bens ambientais, segundo Morato Leite se dá tendo em vista:

(...) o bem ambiental não pode ser rotulado como bem público, devendo, sim, ao contrário, ser considerado um bem de interesse público, cuja administração, uso e gestão devem ser compartilhados e solidários com toda comunidade, inspirados em um perfil de democracia ambiental. (...) 
Na construção do Estado democrático, em termos ambientais, deve-se destacar um sistema legislativo que viabilize a coletividade a participar das decisões ambientais, obter informações indispensáveis para a tomada de consciência e emitir opiniões sobre o tema.

Portanto, nota-se que partindo-se dos malefícios ocasionados em razão da má utilização dos recursos naturais, comprometendo sua qualidade e até mesmo a perpetuidade de sua existência, passa-se a ponderar as consequências que esta crise em torno dos recursos ocasiona para a sociedade, de forma que já não se sustenta a continuidade do Estado que exclua a proteção ambiental separada da proteção da sociedade.

O problema ambiental, como se depreende, altera as visões acerca da própria razão de existir do Estado, que passa a resguardar cada vez mais direitos de natureza difusa (onde não é possível determinar os titulares) e de natureza coletiva (transindividuais, mas cuja titularidade é possível de ser determinada). Passa-se a introduzir novos elementos para a consideração do Direito, do Estado e da Justiça.

\section{RESPOSTAS POLÍTICO-JURÍDICAS ÀS CRISES SOCIOAMBIENTAIS: A EXPRESSÃO DO DIREITO PELA VIA PRINCIPIOLÓGICA}

\subsection{Especificidades socioambientais, incompletudes do sistema político-normativo e a utilização de normas- princípio}

As constantes transformações da sociedade acabam encontrando no sistema político-jurídico alguns obstáculos para serem observados por aqueles que efetivamente exercem o poder político. Uma legislação totalmente voltada ao conteúdo do texto pode não responder de forma adequada aos anseios e necessidades de observância de certos grupos de direitos, especialmente quando se trata de sociedades dotadas de relevante complexidade social.

No entanto, deve-se recordar que o sistema normativo, segundo Robert Alexy está composto de normas-regras e de normas-princípio.

As normas-regras, segundo o autor, referem-se ao âmbito da validade jurídica, enquanto as normas-princípios corresponderiam a mandamentos de otimização ligados aos valores defendidos pela sociedade, integrando de igual forma o sistema de normas do Direito. Tais princípios são dotados de um grau mais elevado de abstração e relatividade, se comparados às regras, e podem ser invocados em um maior número de possibilidades fáticas ou jurídicas, e satisfeitos em graus determinados dependendo de cada caso concreto no qual 
se aplica a regra da proporcionalidade. Desta forma, realiza-se um sopesamento dos princípios, identificando-se, assim, qual deles deverá possuir maior relevância (ALEXY, 2008).

Assim, os princípios corresponderiam a "preceitos que consagram os valores mais importantes (ou cuja chancela jurídica é reputada mais convincente) num determinado contexto histórico, e que só podem fazê-lo adequadamente por meio de enunciados vagos e ajustáveis” (ROTHENBURG, 2003, p. 81).

Nesse sentido, os princípios demonstram-se norteadores da interpretação do sistema jurídico, devendo ser observados para uma compreensão do direito o mais próxima da concretização de seus objetivos. Os princípios em direito, portanto, possuem uma notável função hermenêutica, além de também poderem ser observados diretamente.

A utilização dos princípios no Direito, no entanto, possui algumas nuances polêmicas, principalmente no que se refere à abertura de suas definições, que permite a aplicação dessa categoria normativa a um número maior de situações, incluindo a possibilidade dada ao juiz de aplicar as regras jurídicas utilizando de maior discricionariedade para utilização de um ou de outro princípio.

Nesse sentido, Francischetto (2007, p. 48) explica que, resumidamente, os princípios possuem três funções básicas na ciência jurídica: a) função fundamentadora, o que significa que os princípios devem guiar os legisladores na elaboração de normas jurídicas; b) função orientadora da interpretação, especificamente quando da aplicação de normas por parte do judiciário e c) função de fonte subsidiária, uma vez que, caso falte a legislação em determinado ponto, o direito possui meios de resolver a lide, cabendo à consideração dos princípios a carência de possíveis lacunas. No entanto, verifica-se que a aplicação dessas funções, por vezes mostra-se controvertida.

\subsection{Aspectos polêmicos quanto à utilização de princípios constitucionais em detrimento das normas-regras}

Um dos aspectos mais polêmicos trata da possibilidade de aplicação direta no caso concreto pelo juiz de Direito, utilizando-se da ponderação de princípios, ao invés da subsunção à norma.

Esta possibilidade é corroborada pelo movimento neoconstitucionalista, que tomou força a partir da constatação de que os direitos fundamentais somente conseguiam efetivação se estivessem positivados pelas leis, já que não havia atribuição de força normativa às Constituições, sendo a cultura jurídica da época caracterizada pelo "legicentrismo" (SARMENTO, 2010, p. 2). Esta cultura jurídica, porém, vê-se profundamente alterada com as ocorrências da Segunda Guerra Mundial, onde as maiorias políticas atuavam de forma a dar substrato para o cometimento de diversas barbáries contra a humanidade (SARMENTO, 2012, 
p. 2), não havendo formas mais eficazes de garantia de direitos fundamentais que não estivessem claramente positivados.

Portanto, segundo a visão neoconstitucional,

No lugar de concepções estritamente majoritárias do princípio democrático, são endossadas teorias da democracia mais substantivas que legitimam amplas restrições aos poderes do legislador em nome dos direitos fundamentais e da proteção das minorias. (SARMENTO, 2011, p. 14)

Neste contexto, o autor considera que a aplicação de princípios segundo o viés do neoconstitucionalismo possui um papel fundamental para a concretização da Constituição Brasileira, principalmente quanto aos direitos de certas parcelas da população, de modo que o autor defende este mecanismo para a defesa dos direitos fundamentais e para a proteção das minorias (SARMENTO, 2011, p. 14).

No entanto, a adoção de uma postura neoconstitucionalista indiscriminada pode conduzir à disseminação de um discurso perigoso. Sobre o neoconstitucionalismo no Brasil, Sarmento comenta que o Judiciário brasileiro tem pecado por excesso quando deposita somente no Poder Judiciário a esperança da garantia dos direitos fundamentais e das minorias e se propaga a ideia de que voto e política não são importantes (SARMENTO, 2011, p. 14).

Além disso, resta o dilema a respeito do conflito existente entre o Constitucionalismo e a Democracia, especialmente em se tratando da possibilidade de revisão judicial, onde o Judiciário se vê diante da criação de normas, o que "fugiria" de sua função típica de atividade judiciária. Portanto, a polêmica em torno da atividade criadora do juiz pode não ser fruto direto da democracia (já que os juízes não são eleitos democraticamente pelo povo); mas essa atividade é compatível com ela (CONRADO, 2008).

Assim, cabe a consideração da atividade do Judiciário dentro dos limites democráticos, sendo esta um importante meio para efetivação de direitos socioambientais e dos direitos de minoria pela possibilidade de aplicação de princípios que se adéqüem às particularidades socioambientais.

\subsection{Princípios relacionados ao desenvolvimento e à necessidade de preservação ambiental}

Um dos princípios mais significativos para o tratamento da questão do meio ambiente refere-se ao princípio do desenvolvimento sustentável, que ganhou uma dimensão global através do Relatório Brundtland, de 1987 da Comissão Mundial sobre o Meio Ambiente e Desenvolvimento. Esse Relatório, conhecido como "Nosso Futuro Comum" determinou que da expressão "desenvolvimento 
sustentável" depreende-se que a fruição dos recursos naturais pela presente geração, não deve prejudicar o mesmo direito das gerações futuras.

No entanto, a proteção dos recursos naturais ainda encontra obstáculos na forma como se desenvolvem as relações de produção vigentes (FRACALANZA, 2005), o que torna complexa a realização de uma exploração natural que observe os princípios do desenvolvimento sustentável, surgido como principal bandeira entre a vasta gama de tentativas de rever o comportamento da humanidade em face de seu trato para com o meio ambiente. Esses obstáculos, quando se referirem à atuação do Estado, por meio de políticas públicas e por meio da aplicação do Direito ao caso concreto, podem ser suavizados pela observância dos princípios relacionados à proteção socioambiental e que foram absorvidos enquanto valores sociais.

A cultura desenvolvimentista (expressa também pelo princípio do direito ao desenvolvimento) constitui um valor que comumente se choca a outros princípios igualmente relevantes à sociedade, como por exemplo, o princípio da responsabilidade intergeracional e do direito à qualidade do meio ambiente. Para explicar esta incompatibilidade, que envolve questões ambientais em contraposição às necessidades econômicas, Lutzemberguer (2000, p. 10) sustenta que "o simples dogma básico do pensamento predominante, que diz que uma economia tem que crescer sempre, já é um absurdo. Nada pode crescer sempre, muito menos num espaço limitado", demonstrando o entendimento de que o crescimento econômico não deve prevalecer acima dos valores sociais que o sustentam simplesmente pelo fato de que a observância deste crescimento somente é impraticável.

No entanto, é possível observar que a dinâmica da sociedade já tem tratado de reformular alguns conceitos que se refletem diretamente nas políticas públicas que constituem o Estado e são reguladas pelo Direito, a exemplo das ideias de justiça e desenvolvimento.

José Eli da Veiga (2010, p. 17), por exemplo, explica a evolução do termo através de três distintos aspectos: a) desenvolvimento como crescimento econômico; b) desenvolvimento como algo inalcançável, um mito ou c) desenvolvimento como um ideal que não pode ser "amesquinhado" como mero desenvolvimento econômico, nem tampouco considerado como mito, mas que deva considerar os aspectos humanos.

Para que se chegue ao mais próximo possível dessa terceira visão apresentada, defende o autor que é preciso superar as bases errôneas em que se tem pautado essa visão de desenvolvimento:

A humanidade interage com o meio no empenho de efetivar suas potencialidades. Por isso, na base da reflexão sobre esse tema existe implicitamente uma teoria geral do homem, uma antropologia filosófica. E é a insuficiência dessa teoria que permite entender o freqüente deslizamento para o reducionismo econômico e sociológico (VEIGA, 2010, p. 30). 
Ou seja, depreende-seque agrande discussão em tornodo desenvolvimento remete evolução de valores sobre a atuação do ser humano no planeta. Mais adiante o autor argumenta que, não se sabe em qual momento, a humanidade passou a favorecer a criação de técnicas e não de valores substantivos que deveriam nortear suas atividades (VEIGA, 2010, p. 31), sinalizando a necessidade de reformular esses pensamentos que trouxeram tantos danos à vida em geral.

Um dos autores de maior contribuição para a "reforma" do conceito de desenvolvimento, o economista Amartya Sen ${ }^{1}$, contribui para o estabelecimento de uma visão de desenvolvimento mais voltada ao atendimento das necessidades sociais, o mais próximo possível da ideia de "caminho do meio":

(...) atenta-se particularmente para a expansão das "capacidades" das pessoas de levar o tipo de vida que elas valorizam - e com razão. Essas capacidades podem ser aumentadas pela política pública, mas também, por outro lado, a direção da política pública pode ser influenciada pelo uso efetivo das capacidades participativas do povo. Essa relação de mão dupla é central na análise aqui apresentada. (...). O êxito de uma sociedade deve ser avaliado, nesta visão, primordialmente, segundo as liberdades substantivas que os membros dessa sociedade desfrutam (...). Ter mais liberdade melhora o potencial das pessoas para cuidar de si mesmas e para influenciar o mundo, questões centrais para o processo de desenvolvimento (SEN, 2010, p. 33).

Assim, ao observar-se a falta ou deturpação da consideração dos valores norteadores das atividades humanas, na ideia de Sen, é oferecida uma alternativa coerente rumo a uma nova concepção dos valores defendidos pela humanidade. Mais do que pensar a questão do desenvolvimento como o aumento do desempenho econômico de determinado Estado, é preciso pensar, antes, no oferecimento de oportunidades às pessoas de desenvolverem suas capacidades, de acordo com o estilo de vida que julgarem adequado às suas necessidades, o que obviamente inclui a valorização da qualidade do meio ambiente. Especificamente, ao pensar no trato do ser humano para com o meio ambiente, deve-se buscar a observância dessa mesma liberdade.

Finalmente, é necessário considerar que aos novos valores de desenvolvimento e de preservação ambiental considerando o fator humano agregam-se ao socioambientalismo, que pressupõe a ruptura de um paradigma de desenvolvimento, que é hegemônico nas sociedades ocidentais modernas (BARBOSA, 2008, p. 82).

No entanto, a Cláudia Barbosa considera como mais relevante a observância do paradigma do socioambientalismo pelo Poder Judiciário, uma vez que este propõe a ruptura com o modelo de desenvolvimento que o associa ao crescimento econômico, o que não valeria para a noção de desenvolvimento 
sustentável, que pressuporia a manutenção do padrão de crescimento para depois distribuí-lo aos países mais pobres. (BARBOSA, 2008, p. 82)

Assim, a autora conclui no sentido de que para tornar a atuação do Poder Judiciário mais justa e efetiva, é necessário que este observe os valores advindos do socioambientalismo, com ênfase na proteção de direitos não-individuais, dentre outros pontos relevantes. (BARBOSA, 2008, p. 83). Tendo em vista as incorporações de valores socioambientais no contexto das sociedades, mostrase um notável avanço quanto à observância de direitos fundamentais e aqueles pertencentes às minorias, que, se observados pela ótica de uma democracia rígida não seria capaz de abarcar a complexidade das peculiaridades socioambientais, especialmente no contexto brasileiro.

\section{A PROPOSIÇÃO DE REFORMULAÇÃO NAS NOÇÕES DE ESTADO DE DIREITO E CONSIDERAÇÃO DA JUSTIÇA SOCIOAMBIENTAL PELA INCLUSÃO DE NOVOS SUJEITOS E INSTITUCIONALIDADES}

De acordo com as proposições já trabalhadas, nota-se que, por um lado, a própria evolução da sociedade tem dado conta (ainda que a passos lentos) de modificar as possibilidades de garantia de direitos pela via da atuação estatal, fazendo com que o Direito sofra constantes mutações em sua estrutura.

Por outro lado, dentre tantas modificações que foram sendo inseridas nos sistemas normativos, Capella também destaca a abertura do Estado e a própria “desrregulação jurídica”. Esta característica pode ser pensada também dentro do movimento neoconstitucionalista, em que se nota a relativização da norma-regra em favor da aplicação de ponderação baseada na norma-princípio. O movimento destacado pelo autor, no entanto, refere-se à perda da imperatividade do Estado, "contratualizando" o interesse público, misturando-o ao privado e transferindo a capacidade de decisão do público para o privado. (CAPELLA, 2008)

Além dessas modificações, o autor nota também uma forte mudança no que tange às fontes do Direito, que se vê demasiadamente influenciado pela lex mercatoria e pela manu militari, demonstrando que as questões de conflitos internacionais também acabam exercendo um poder de "criação de norma" no direito nacional. (CAPELLA, 2008)

Ao contrário do que se tentou demonstrar ao longo deste paper, apesar de haverem movimentos para tornar o Direito mais apto a responder às demandas sociais, existem movimentos contrários de "desrregulação" que acarretam a adoção de soluções simplistas e que se distanciam dos propósitos iniciais (CAPELLA, 2008, p. 352). A observância de tal situação, no entanto, deve servir de preocupação para que o poder estatal exerça seus propósitos, com o objetivo de não comprometer os direitos fundamentais e os direitos da minoria. 
Assim, diante do desafio de encarar a diversidade socioambiental, Boaventura de Souza Santos (2009) propõe uma transição das respostas fracasfracas para as respostas fracas-fortes, saindo-se do mínimo de consciência possível (pela utilização de respostas simplistas) até atingir um nível máximo (o que corresponderia às respostas fortes-fortes). Diante da construção de possibilidades, levando-se em conta esses pressupostos, o autor defende uma sociologia das emergências, captando-se os elementos da douta ignorância e da ecologia dos saberes. A partir de então, seria possível pensar a diversidade convidando a novos encontros culturais.

O exemplo mais significativo deste esforço da construção de novos elementos jurídicos na América Latina remete às novas constituições da Bolívia e do Equador, que consagram a consideração da diversidade sociambiental pelos princípios da Suma Qamaña, "vivir bien" ou "bien vivir".

A Constituição Boliviana traz em seu texto a noção de "vivir bien" como príncípio ético-moral da sociedade plural, fazendo dela o objetivo primordial da sociedade. Assim, a educação, o modelo econômico e a eliminação da pobreza deverão estar orientados para o "vivir bien". De forma análoga, no tocante à natureza, será possível observar em vários pontos, a defesa de sua gestão respeitando-se a soberania e o interesse do povo. Também é possível observar nessa Constituição a remissão expressa à observância do ideal de desenvolvimento sustentável e de respeito à natureza. A Constituição Boliviana prevê, ainda, a soberania dos povos indígenas sobre os recursos existentes em seus espaços, segundo as normas legais para sua proteção, mas utilizando-se de suas próprias normas e formas harmônicas de relação com a natureza.

A Constituição equatoriana, por sua vez, utiliza-se de um termo análogo, o "buen vivir" também como princípio a ser observado, mas elenca uma série de direitos necessários à sua constituição. Estabelece, ainda, que as pessoas poderão beneficiar-se dos recursos naturais de acordo à noção desse "buen vivir" e que as políticas públicas de modo geral deverão por ela ser orientadas. A mediação de conflitos também deve ser orientada pelo mesmo paradigma, assim como as formas de desenvolvimento, que também deverão respeitar as diferenças. Também é possível observar nessa Constituição a presença de um rol de deveres do Estado, das pessoas individualmente e das sociedades organizadas para a consecução do chamado "buen vivir", bem como diversos dispositivos interessantes como, por exemplo, a limitação do endividamento público à não afetação do "buen vivir". Além disso, há todo um título da Constituição dedicado ao estabelecimento de como o Estado, juntamente com a sociedade deverão alcançar esse paradigma. No entanto, um dos pontos altos dessa Constituição é a inclusão dos direitos da Pachamama (mãe Terra), que assume o lugar de novo sujeito de Direito, revolucionando a própria teoria do Direito.

Os novos valores trazidos por meio dessas duas Constituições, além de outras experiências na América Latina deram origem ao movimento do "Novo 
Constitucionalismo Latinoamericano" que tem se desenvolvido como tentativa de fornecer ao sistema constitucional dos países latinoamericanos uma estrutura e bases ideológicas mais próximas à sua realidade socioambiental.

\section{CONSIDERAÇÕES FINAIS}

É possível afirmar, com considerável substrato teórico, que o fato de que a crise relacionada aos recursos naturais tem ajudado a modificar alguns padrões sociais, incorporando novos valores à sociedade, é uma realidade da qual o Direito não pode permanecer alheio. De fato esta adequação do Direito pode ser observada pelos constantes movimentos que buscam a criação e interpretação de normas de forma a observar preceitos que tentem minimizar a realidade dos problemas de ordem socioambiental.

Os valores decorrentes dos paradigmas do desenvolvimento sustentável e do socioambientalismo passam a compor a sociedade de tão forma que agregam novos elementos ao Estado e ao Direito, modificando substancialmente suas bases mais fundamentais.

A atuaçãodoJudiciáriolegitimada por teoriascomoa neoconstitucionalista, por exemplo, demonstra essa modificação pelo aumento substancial da capacidade criadora do juiz, o que se mostrou algo positivo quando se trata de resguardar direitos fundamentais e direitos sociais relacionados às minorias. No entanto, resta ressalvar que esta atuação deve manter-se fiel às instituições jurídicas, utilizando-se dos princípios para tornar possível a aplicação do Direito que se aproxime tanto quanto possível dos ideais de justiça e equidade, especialmente no que se refere aos temas de maior complexidade pelas inúmeras peculiaridades inerentes às questões socioambientais.

\section{NOTA}

$1 \mathrm{O}$ economista indiano Amartya Sen foi um dos idealizadores do Índice de Desenvolvimento Humano, opondo-se frontalmente à análise das economias dos países unicamente pelo viés da renda per capta ou do Produto Interno Bruto, levando em consideração as dimensões humanas e a criação de oportunidades para tornar possível a liberdade das pessoas. Ganhou o prêmio Nobel de Economia pela obra "Desenvolvimento como Liberdade"

\section{Referências Bibliográficas}

ALEXY, Robert. Teoria dos Direitos Fundamentais. 5ed. São Paulo: Malheiros, 2008.

BARBOSA, Claudia Maria. Reflexiones sobre um sistema judicial eficaz em uma sociedade socioambienalmente responsable. In: El outro derecho. N. 39. Instituto Latinoamericano de Servicios Legales Alternativos. Derecho y estudios socioambientales en Brasil, 2008. 
CAPELLA, Juan Ramón. Fruta prohibida: una aproximaxión histórico-teorética el estudio del derecho y del estado. Madrid: Trotta, 2008.

CAPPELLETTI, Mauro. Juízes legisladores? Porto Alegre: SAFabris, 1993.

CAPRA, Fritjof. As conexões ocultas. São Paulo: Cultrix, 2006.

CONRADO, Hübner Mendes. Direitos fundamentais, separação de poderes e deliberação. Tese de doutorado. São Paulo: Universidade de São Paulo, 2008.

FRACALANZA, Ana Paula. Água: de elemento natural à mercadoria. In: Revista Sociedade \& Natureza. Uberlândia: Editora, v. 17, 21-36, dezembro 2005.

FRANCISCHETTO, Gilsilene Passon Picoretti. Hermenêutica filosófica em HansGeorg Gadamer: a contribuição dos princípios. In: CARVALHO, Janete Magalhães e FRANCISCHETTO, Gilsilene Passon Picoretti (Coord.). Discursos introdutórios na ciência do Direito. Rio de Janeiro: Editora Lúmen Juris, 2007.

KELSEN, Hans. Teoria geral do direito e do estado. 4ed.. São Paulo: Martins Fontes, 2005.

LEITE, José Rubens Morato. Dano Ambiental: do individual ao coletivo extrapatrimonial. São Paulo: Revista dos Tribunais, 2003.

ROTHENBURG, Walter Claudius. Princípios constitucionais. 2 Tiragem.Porto Alegre: Sergio Antônio Fabris Editor, 2003.

SACHS, Ignacy. Desenvolvimento: includente, sustentável, sustentado. Rio de Janeiro: Garamond, 2004.

SANTILLI, Juliana. Socioambientalismo e novos direitos: proteção jurídica da diversidade biológica e cultural. São Paulo: Peirópolis, 2005.

SANTOS, Boaventura de Souza. MENESES, Maia Paula (orgs). Epistemologias do Sul. Coimbra: Almedina, 2009.

SARMENTO, Daniel. O neoconstitucionalismo no Brasil: riscos e possibilidades. Disponível Editora Forum.

SEN, Amartya. Desenvolvimento como liberdade. São Paulo: Companhia das Letras, 2010.

VEIGA, José Eli. A emergência socioambiental. São Paulo: Editora Senac São Paulo, 2007. 


\section{Resumo}

O presente paper trata de tecer alguns comentários sobre a influência dos princípios jurídicos, especialmente os constitucionais, para as mudanças nas noções de Direito, Estado e Justiça. Para tanto, parte-se das transformações ocorridas na sociedade por conta das crises socioambientais, passando pela institucionalização de novos valores jurídicoconstitucionais que passam a compor a ordem normativa e devem ser observados tanto para a criação quanto para a aplicação das normas de Direito. Também se busca trazer alguns breves comentários sobre algumas tentativas mais radicais de incorporação desses novos valores, compondo, inclusive, novas formas de constitucionalismo, que passam a incluir os valores e princípios socioambientais na consideração dos objetivos sociais, inclusive relacionados às questões desenvolvimentistas.

Palavras-chave: Princípios constitucionais. Estado. Direito. Neoconstitucionalismo. 


\title{
SOCIAL AND ENVIRONMENTAL LAW PRINCIPLES IN THE EVOLUTION OF NOTIONS OF LAW, STATE AND JUSTICE
}

\begin{abstract}
This paper analizes the influence of legal principles, especially constitutional, to the changes in notions of Law, State and Justice. Therefore, it starts from the changes taking place in society because the social and environmental crises, through the institutionalization of new legal-constitutional values that became part of the normative order and must be observed for the creation and for the application of law standards. It also seeks to bring some brief comments on some of the more radical attempts to incorporate these new values, composing, including new forms of constitutionalism, passing to include the values and environmental principles into consideration the social, including related to developmental issues.
\end{abstract}

Keywords: Constitutional principles. State. Law. Neoconstitutionalism. 